\title{
Dominant role of splenic marginal zone lipid rafts in the classical complement pathway against S. pneumoniae
}

Seung Woo Yang ${ }^{1,2,3}$, Jin-Yeon Park', Hyeongjwa Choi ${ }^{4}$, Tae Jin Yun ${ }^{5}$, Woo-Sung Choi ${ }^{6}$, Min-Kyung Kim', Yun Kyung Lee ${ }^{1}$, Min Park ${ }^{1,2}$, Yihwa Jin ${ }^{1,2}$, Jin Soo Joo ${ }^{7}$, In-Soo Choi ${ }^{8}$, Seung Hwa Park, Han Sung Hwang ${ }^{2}$ and Young-Sun Kang ${ }^{1,7}$

\begin{abstract}
Lipid rafts (LRs) play crucial roles in complex physiological processes, modulating innate and acquired immune responses to pathogens. The transmembrane C-type lectins human dendritic cell-specific intercellular adhesion molecule-3-grabbing nonintegrin (DC-SIGN) and its mouse homolog SIGN-R1 are distributed in LRs and expressed on splenic marginal zone (MZ) macrophages. The DC-SIGN-C1q or SIGN-R1-C1q complex could mediate the immunoglobulin (lg)-independent classical complement pathway against Streptococcus pneumoniae. Precise roles of LRs during this complement pathway are unknown. Here we show that LRs are indispensable for accelerating the DC-SIGN- or SIGN-R1-mediated classical complement pathway against S. pneumoniae, thus facilitating rapid clearance of the pathogen. The trimolecular complex of SIGN-R1-C1q-C4 was exclusively enriched in LRs of splenic MZ macrophages and their localization was essential for activating C3 catabolism and enhancing pneumococcal clearance, which were abolished in SIGN-R1-knockout mice. However, DC-SIGN replacement on splenic MZ macrophage's LRs of SIGN-R1-depleted mice reversed these defects. Disruption of LRs dramatically reduced pneumococcal uptake and decomposition. Additionally, DC-SIGN, C1q, C4, and C3 were obviously distributed in splenic LRs of cadavers. Therefore, LRs on splenic SIGN-R1+ or DC-SIGN ${ }^{+}$macrophages could provide spatially confined and optimal bidirectional platforms, not only for usual intracellular events, for example recognition and phagocytosis of pathogens, but also an unusual extracellular event such as the complement system. These findings improve our understanding of the orchestrated roles of the spleen, unraveling a new innate immune system initiated from splenic MZ LRs, and yielding answers to several long-standing problems, including the need to understand the profound role of LRs in innate immunity, the need to identify how such a small portion of splenic $\mathrm{SIGN}-\mathrm{R} 1^{+}$macrophages ( $<0.05 \%$ of splenic macrophages) effectively resist $S$. pneumoniae, and the need to understand how LRs can promote the protective function of DC-SIGN against S. pneumoniae in the human spleen.
\end{abstract}

\footnotetext{
Correspondence: Young-Sun Kang (kangys1967@naver.com)

${ }^{1}$ Department of Biomedical Science and Technology, Konkuk University,

1 Hwayang-dong, Gwangjin-gu, Seoul 143-701, Republic of Korea

${ }^{2}$ Department of Obstetrics and Gynecology, Division of Maternal and Fetal

Medicine, Research Institute of Medical Science, Konkuk University School of

Medicine, 120 Neungdong-ro, Gwangjin-gu, Seoul 05029, Korea

Full list of author information is available at the end of the article.

These authors contributed equally: Seung Woo Yang, Jin-Yeon Park

Edited by A. Rufini
}

\section{Introduction}

Lipid rafts (LRs) are small $(10-200 \mathrm{nM})$, highly dynamic, detergent-resistant membrane fractions enriched in cholesterol and glycosphingolipid content on the plasma membranes of eukaryotic cells ${ }^{1,2}$. Although LRs comprise only a small percentage of the cell surface area $^{3}$, their sizes can increase by coalescence with other raft units $^{4,5}$, providing spatiotemporal platforms for many

\section{(c) The Author(s) 2019}

(c) Open Access This article is licensed under a Creative Commons Attribution 4.0 International License, which permits use, sharing, adaptation, distribution and reproduction cc. in any medium or format, as long as you give appropriate credit to the original author(s) and the source, provide a link to the Creative Commons license, and indicate if changes were made. The images or other third party material in this article are included in the article's Creative Commons license, unless indicated otherwise in a credit line to the material. If material is not included in the article's Creative Commons license and your intended use is not permitted by statutory regulation or exceeds the permitted use, you will need to obtain permission directly from the copyright holder. To view a copy of this license, visit http://creativecommons.org/licenses/by/4.0/. 
molecular entities ${ }^{6}$. LRs play crucial roles in complex physiological processes, such as phagocytosis, receptor-receptor associations, receptor-pathogen associations, and signal transduction in many pathological situations ${ }^{1,2,7-9}$, modulating innate and acquired immune responses ${ }^{10}$.

The complement system is important for several innate and adaptive resistance mechanisms and consists of a highly regulated cascade of more than 30 serum complement proteins that can be triggered by the recognition of a microbe ${ }^{11}$. This system can be activated through classical, soluble mannose-binding lectin (MBL), and alternative pathways ${ }^{12,13}$. A pivotal step in the complement pathways is assembly of a C3 convertase, which digests $\mathrm{C} 3$ to form microbial binding $\mathrm{C} 3$ fragments Because C3 fragments ${ }^{14}$, such as C3b, C3bi, and C3d, serve as ligands for complement receptors, their reciprocal binding promotes the uptake and killing of microbes by phagocytes ${ }^{15}$. Thus, the complement system provides a major extracellular defense mechanism against infectious organisms $^{16}$

Various immune receptors in LRs, such as Fc receptors $^{17,18}$, cytokine receptors ${ }^{19-21}, \mathrm{~B}$ cell receptors ${ }^{22}$, and $\mathrm{T}$ cell receptors ${ }^{23}$, increase their binding capacity through clustering ${ }^{24}$ and facilitate signaling to favor the clearance of intracellular pathogens ${ }^{10}$. Some innate pattern recognition receptors, such as Toll-like receptors and transmembrane C-type lectins, translocate to LRs upon stimulation with specific agonists ${ }^{25-30}$, thus demonstrating the importance of this membrane partitioning for the innate immune recognition of various pathogens ${ }^{3}$. In addition, various complement receptors (CR2, CR3, and globular $\mathrm{C} 1 \mathrm{q}$ receptor $(\mathrm{gC} 1 \mathrm{qR}))^{31,32}$ and complement regulatory proteins $(\mathrm{CD} 46, \mathrm{CD} 55 \text {, and } \mathrm{CD} 59)^{33,34}$ are distributed in the LRs of immune cells.

Transmembrane C-type lectin human dendritic cellspecific intercellular adhesion molecule-3-grabbing nonintegrin (DC-SIGN, CD209) and its murine homolog SIGN-R1 exhibit several common specificities, such as acting as the principal receptors for the pneumococcal capsular polysaccharide of S. pneumoniae (CPS) $)^{35,36}$ and human immunodeficiency virus- $1^{37,38}$, binding to the complement $\mathrm{C} 1 \mathrm{q}^{24,39}$, and showing distribution in LRs in vitro $^{29,30}$. Additionally, SIGN-R1 can initiate an immunoglobulin (Ig)-independent classical complement pathway by interacting with $\mathrm{C} 1 \mathrm{q}$ against $S$. pneumoniae, particularly on the cellular surface of splenic marginal zone (MZ) macrophages, facilitating their rapid clearance $^{39}$. Similarly, the DC-SIGN-C1q complex may provide an initiation site for the classical complement pathway under pathogenic conditions ${ }^{24}$.

Although disruption of LRs significantly reduces DCSIGN- and SIGN-R1-mediated pneumococcal phagocytosis, the specific mechanisms are still unknown.
Accordingly, in this study, the role of LRs was examined in C-type lectin-mediated phagocytosis in order to elucidate the role of DC-SIGN in the human spleen.

\section{Results}

LRs on splenic MZ DC-SIGN ${ }^{+}$macrophages may be important for DC-SIGN-mediated uptake and decomposition of $S$. pneumoniae

DC-SIGN transfectants were immunostained for DCSIGN and the raft protein GM-1 ganglioside with fluorescein isothiocyanate (FITC)/cholera toxin B (CTB) subunit. Large aggregates of DC-SIGN were strongly distributed in CTB-enriched vertex regions of the cells (Fig. 1a). Moreover, DC-SIGN monomers and dimers were obviously enriched in LR fractions (fractions 4-6) compared with non-LR fractions (Fig. 1a). Isolation of detergent-resistant raft fractions was confirmed with immunoblotting for flotillin-1 and caveolin-1 as representative markers of planar LRs and caveolae, respectively ${ }^{40}$. The same experiment was performed with SIGN-R1 depletion and DC-SIGN transgenic mice (DC-SIGN ${ }^{\mathrm{BMT}}$ / SIGN-R1 ${ }^{\text {TKO} ; ~ F i g . ~} 1 \mathrm{~b}$ and Supplementary Fig. S1a, b) or human cadavers (Supplementary Fig. S1c). DC-SIGN was obviously expressed in LRs of splenic MZ DC-SIGN ${ }^{+}$cells (Fig. 1c, d and Supplementary Fig. S1d).

Disruption of LRs with methyl- $\beta$-cyclodextrin $(M \beta C D)$, a cholesterol-extracting agent, did not reduce DC-SIGN expression on the cellular surface, but altered its surface distribution pattern (Fig. 1e). Moreover, when DC-SIGN transfectants were incubated with carboxyfluorescein succinimidyl ester (CFSE)-labeled S. pneumoniae, pneumococcal uptake and decomposition were obvious in the cytoplasm, showing disintegrated particles of the pneumococcal capsular polysaccharide of $S$. pneumoniae serotype 14 (CPS14) around the phagocytosed bacterium (Fig. If and Supplementary Fig. S1e). Similar results were observed after pretreatment with actinomycin-D or cycloheximide, which did not affect the plasma membrane structure (Fig. 1f). However, pneumococcal uptake and decomposition were dramatically reduced with disruption of LRs using M $\beta C D$ (Fig. If and Supplementary Fig. S1f) or with inhibition of LR-dependent endocytosis using dynamin inhibitory peptide (DIP) or transfection with dominant-negative dynamin (K44A; Fig. $1 \mathrm{~g}$ and $\mathrm{h}$, respectively), only permitting microbial binding to the cellular surface of DC-SIGN transfectants. The bacterial decomposition ratios were quantitatively calculated (Fig. 1f-h).

\section{LRs on splenic MZ SIGN-R1 ${ }^{+}$macrophages may be important for SIGN-R1-mediated uptake and decomposition of $S$. pneumoniae}

Large aggregates of SIGN-R1 were observed in CTBenriched vertex regions of SIGN-R1 transfectants and strong 


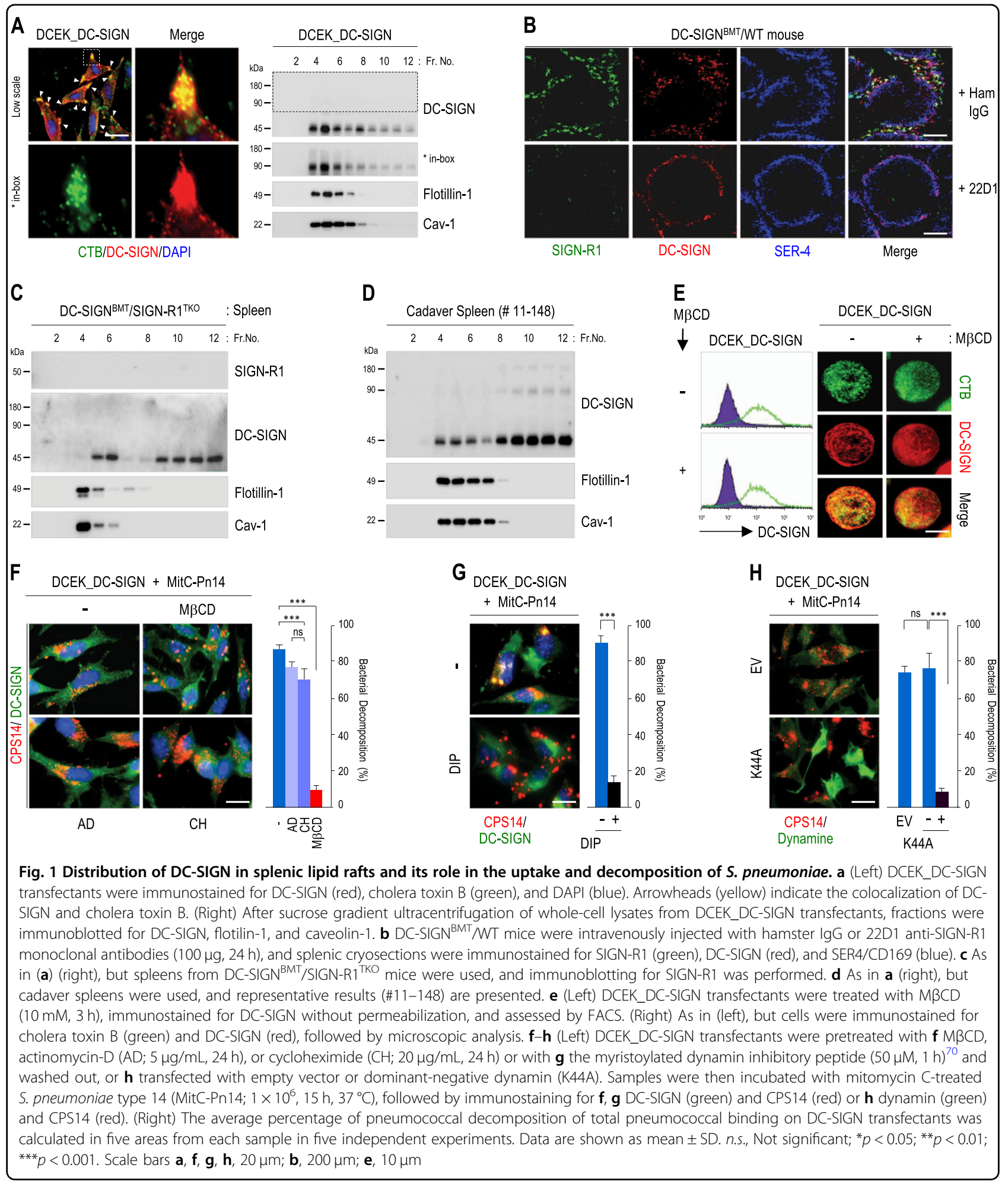

distribution of SIGN-R1 monomers and dimers were obvious in LR fractions (Fig. 2a). In particular, multimers of SIGN-R1 were preformed in LRs (inset in Fig. 2a). In whole fractions of spleens or lymph nodes from wild-type (WT) mice, SIGN-R1 was evident only in LRs of both tissues of WT mice with a higher concentration of SIGN-R1 multimers in LRs than in non-LRs (Fig. 2b), but not from SIGN-R1-knockout (KO) mice (Fig. 2c and Supplementary Fig. S2a). 


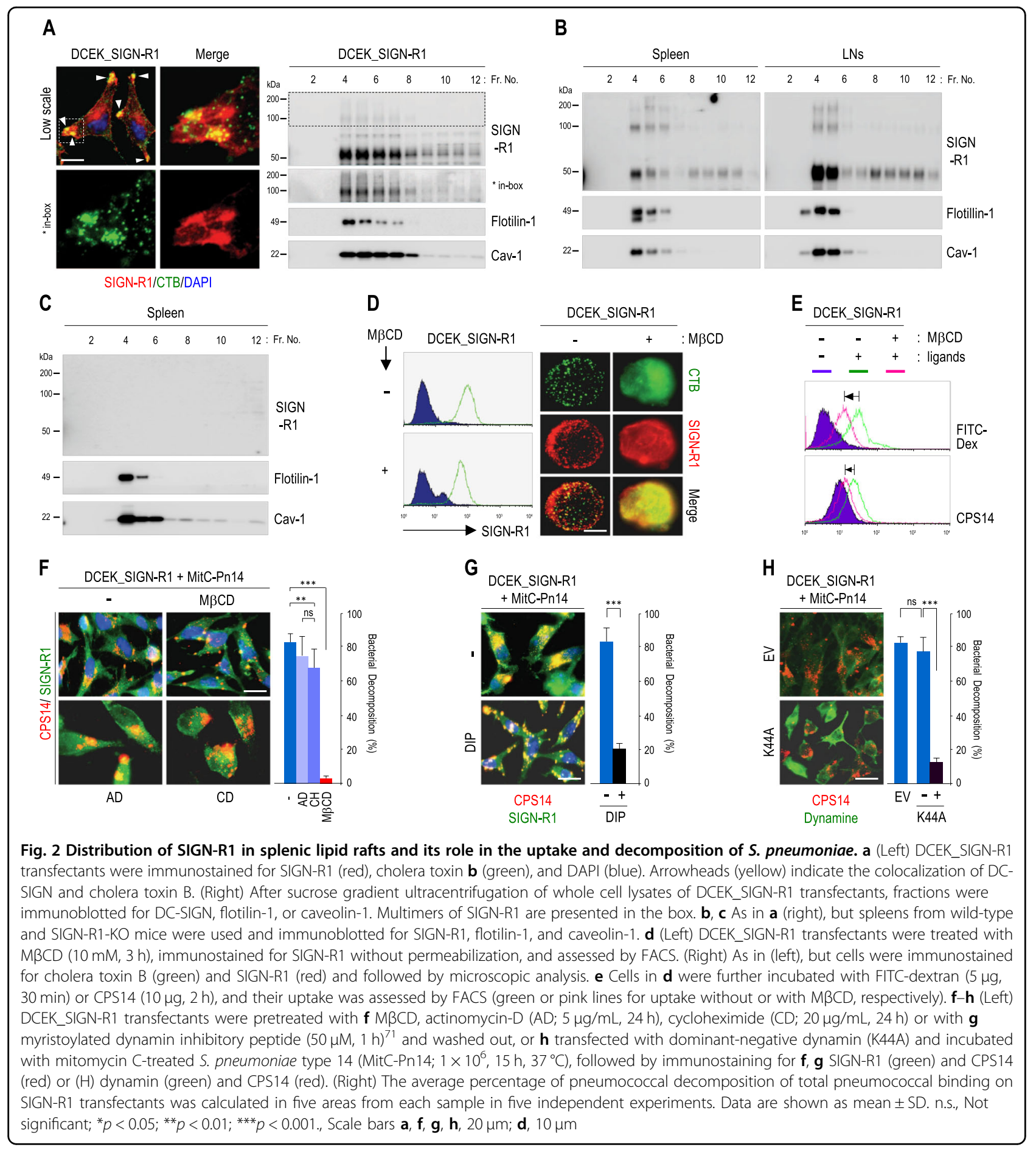

Disruption of LRs with M $\mathrm{MCD}$ did not reduce SIGN-R1 expression on the transfectant cellular surface, but altered its surface distribution pattern (Fig. 2d). However, $M \beta C D$ treatment of SIGN-R1 transfectants reduced the uptake of dextran or CPS14, representative ligands of SIGN-R1 ${ }^{41,42}$ (Fig. 2e). Similarly, when SIGN-R1 transfectants were incubated with S. pneumonia type 14, which has strong binding affinity for SIGN-R1 $1^{41}$, the uptake and decomposition of the organism were evident under control conditions (Fig. 2f and Supplementary Fig. S2b) and in the presence of actinomycin-D or cycloheximide (Fig. 2f). However, M $\beta C D$ treatment of SIGN-R1 transfectants inhibited the uptake and decomposition of S. pneumoniae, only permitting microbial binding to the cellular surface 
(Fig. 2f). Moreover, inhibition of LR-dependent endocytosis using DIP or K44A dramatically reduced the uptake and decomposition of the organism (Fig. 2g, h). The bacterial decomposition ratios were quantitatively calculated (Fig. 2f-h).

LRs of splenic MZ SIGN-R1 ${ }^{+}$macrophages may provide an optimal location for innate recruitment of SIGN-R1 against S. pneumoniae in vivo

SIGN-R1 transfectants were incubated with S. pneumoniae at $37^{\circ} \mathrm{C}$ or $4{ }^{\circ} \mathrm{C}$ or in the presence of $\mathrm{M} \beta C D$, and abundant SIGN-R1 aggregation was observed on the cell surface only at $37^{\circ} \mathrm{C}$ (Fig. 3a, b). When these cells were then fractionated and their LR fractions were immunoblotted for SIGN-R1, SIGN-R1 monomers and multimers were obviously increased in LRs (Fig. 3c). Because SIGN$\mathrm{R} 1^{+}$macrophages rapidly recognized S. pneumoniae in splenic MZs within $1 \mathrm{~h}$ (Fig. 3d), SIGN-R1 distribution in splenic LRs was examined $1 \mathrm{~h}$ after intravenous injection of $S$. pneumoniae. SIGN-R1 complex was obviously increased only in splenic LRs following S. pneumoniae stimulation (Fig. 3e), as confirmed in separate experiments (Supplementary Fig. S3a, cases 1-4).

Similar experiments using intravenous injection of an unencapsulated mutant of S. pneumoniae serotype 14 (mt-Pn14) or Staphylococcus aureus, another grampositive coccal bacterium that does not bind SIGN$\mathrm{R} 1^{41,43}$ showed no increase in SIGN-R1 complex in splenic LRs (Fig. 3f, g), confirming the CPS14 dependent recruitment of SIGN-R1 complex against S. pneumoniae. Next, we examined whether MARCO, a scavenger receptor expressed on partial SIGN-R1 ${ }^{+} \mathrm{MZ}$ macrophages $^{44}$, or SER4/CD169, a cell adhesion molecule expressed on MZ metallophils, were recruited in splenic LRs following S. pneumoniae exposure. Neither target was recruited in splenic LRs following exposure to S. pneumoniae (Fig. 3h).

C1q and C4 are distributed in LRs of splenic MZ SIGN-R1 ${ }^{+}$ macrophages and increased following $S$. pneumoniae exposure in a SIGN-R1-dependent manner in vivo

The expression levels of $\mathrm{C} 1 \mathrm{q}$ and $\mathrm{C} 4$ in whole-cell lysates from the spleens, livers, and lungs of control mice were similar in all tissues (Supplementary Fig. S4b). However, higher levels of $\mathrm{Clq}$ and $\mathrm{C} 4$ were found in splenic LRs than in hepatic or pulmonary LRs or in nonLRs from all tissues (Fig. 4a). Other traditional mediators in different complement pathways (IgM, MBL-C, and factor B) were barely present in LRs from all tissues (Fig. 4b), but were variable in non-LRs (Supplementary Fig. S4c). Following intravenous injection of phosphatebuffered saline (PBS) or S. pneumoniae, simultaneous increases in C1q and C4 were obvious only in splenic LRs, whereas no changes were found in hepatic or pulmonary
LRs or in non-LRs (Fig. 4c). Additionally, no differences in IgM, MBL-C, or factor B levels were found in any fraction (Fig. 4d and Supplementary Fig. S4d).

In SIGN-R1-KO mice, the levels of $\mathrm{C} 1 \mathrm{q}$ and $\mathrm{C} 4$ in whole-cell lysates of all tissues were the same as those in control mice (Supplementary Fig. S4e, b). However, both complements were not increased at all following S. pneumoniae exposure (Fig. 4e). Moreover, increases in $\mathrm{C} 1 \mathrm{q}$ and $\mathrm{C} 4$ were completely abolished in splenic LRs from SIGN-R1 ${ }^{\mathrm{TKO}}$ mice exposed to $S$. pneumoniae (Supplementary Fig. S4f). To determine whether the specific recognition of CPS14 by SIGN-R1 was required for upregulation of $\mathrm{C} 1 \mathrm{q}$ and $\mathrm{C} 4$ in splenic LRs, splenic fractions were immunoblotted for $\mathrm{C} 1 \mathrm{q}$ and $\mathrm{C} 4$. Both complements were not upregulated at all in any splenic fraction following exposure to mt-Pn14 or S. aureus (Fig. 4f, g).

LRs from splenic MZ SIGN-R1 ${ }^{+}$macrophages may provide an optimal location for dominant $\mathrm{C} 3$ activation in response to $S$. pneumoniae in a SIGN-R1-dependent manner in vivo

We examined C3 levels in whole-cell lysates from the spleen, liver, and lung of WT mice, and the lowest expression was observed in the spleen (Supplementary Fig. S5a). However, immunoblotting of their fractions for $\mathrm{C} 3$ showed that constitutive distribution of $\mathrm{C} 3$ was the highest in splenic LRs among LRs of all tissues (Fig. 5a). Furthermore, following intravenous injection of PBS or $S$. pneumoniae, the initial activation of $\mathrm{C} 3$ was most dominant in splenic LRs exposed to $S$. pneumoniae with a dramatic decrease in $\alpha \mathrm{C} 3$, but a relatively minor decrease was observed in splenic non-LRs (Fig. 5b). These results in spleen fractions were confirmed in separate experiments (Supplementary S5b, c).

In sera or splenic fractions from SIGN-R1-KO or SIGNR1 ${ }^{\text {TKO }}$ mice, SIGN-R1 deficiency did not affect C3 levels in sera (Supplementary S5g) or distribution in splenic LRs without pneumococcal challenge (Fig. 5c, top, Supplementary Fig. S5f, g, top), but abolished C3 activation with pneumococcal challenge (Fig. 5c, bottom and Supplementary Fig. S5g, bottom). Moreover, CPS14 was essential for SIGN-R1-mediated C3 activation in splenic LRs because $\mathrm{C} 3$ activation was significantly decreased or abolished in all splenic fractions from WT mice following $\mathrm{mt}-\mathrm{Pn} 14$ or $\mathrm{S}$. aureus challenge, yielding abundant intact $\mathrm{C} 3 \alpha$ and weak or no increases in $43 \mathrm{kDa}$ iC3b (Fig. 5d, e). In C3-depleted mice, C3 deficiency in splenic LRs had no effect on the constitutive distribution of SIGN-R1, C1q, or $\mathrm{C} 4$ in splenic LRs or their increases against S. pneumoniae (Fig. 5f).

When WT cells or SIGN-R1 transfectants were incubated with mouse serum, fixation of $\mathrm{C} 4$ and $\mathrm{C} 3$ was observed only on SIGN-R1 transfectants and was significantly enhanced in SIGN-R1 transfectants in the 


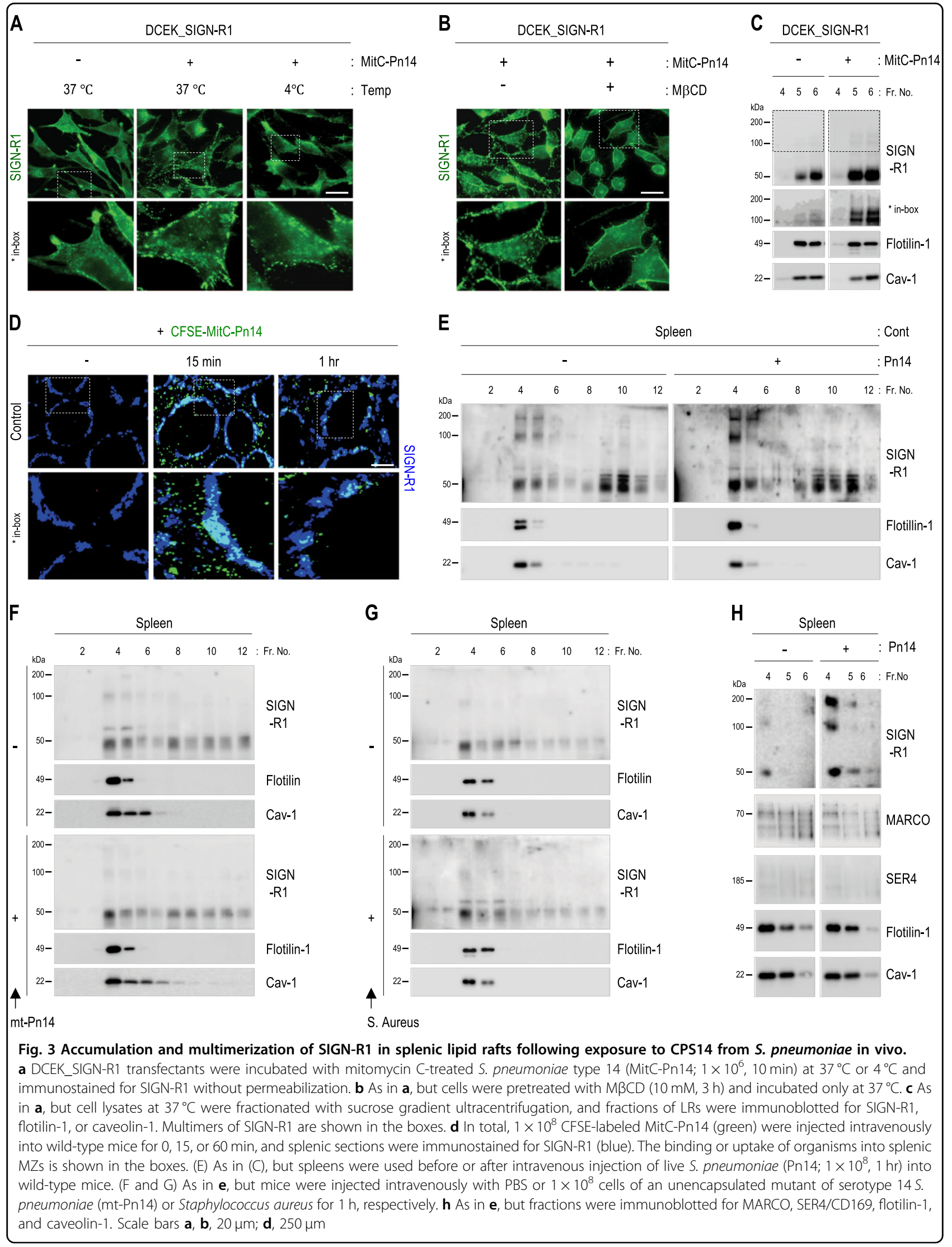




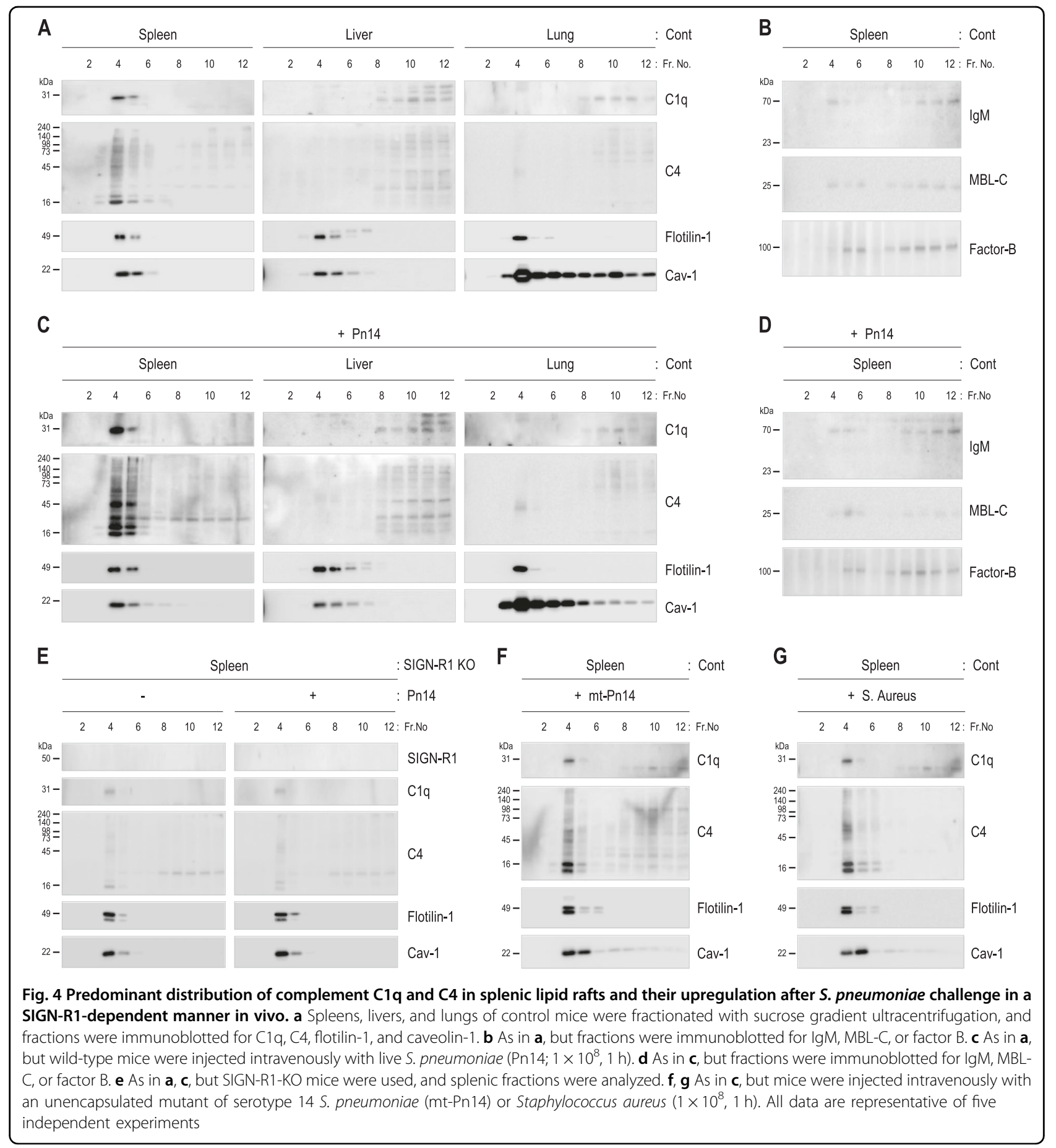

presence of S. pneumoniae (Fig. 5g). Furthermore, fluorescent microscopy revealed the colocalization of $\mathrm{C} 4$ and C3 only in SIGN-R1 transfectants (Fig. 5h and Supplementary Fig. S5h), indicating that $\mathrm{C} 3$ activation was specifically generated at the same location on $\mathrm{SIGN}-\mathrm{R} 1^{+}$cells in which the SIGN-R1-mediated classical complement pathway was initiated.
Enrichment of SIGN-R1 and C1q enhances the opsonization, uptake, and decomposition of $S$. pneumoniae

Addition of SIGN-R1 significantly enhanced the fixation of $\mathrm{Clq}$ on the pneumococcal surface (Fig. 6a). Sequentially, the increased concentration of $\mathrm{C} 1 \mathrm{q}$ also accelerated the opsonization of $\mathrm{iC} 3 \mathrm{~b}$ in response to 


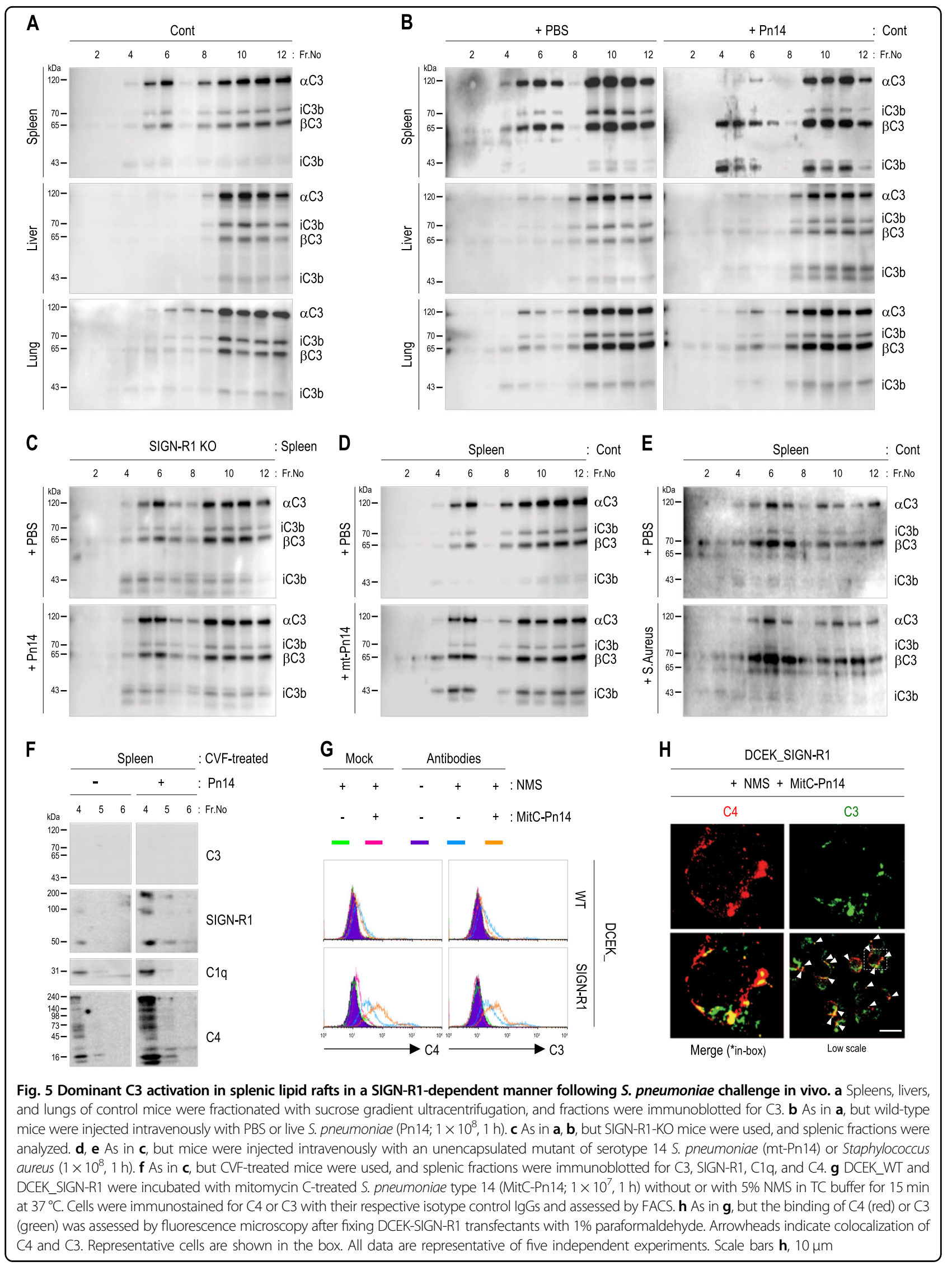




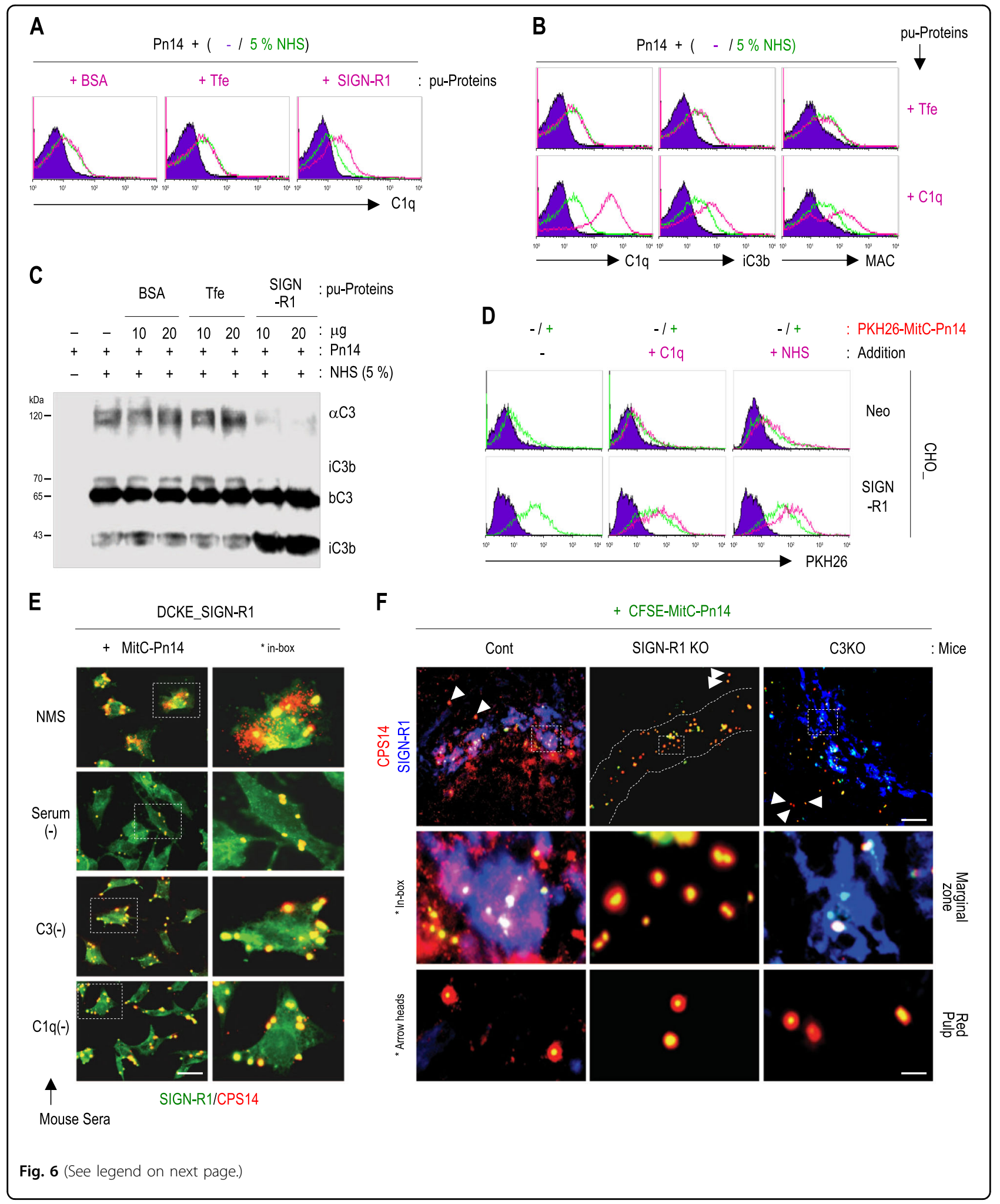

S. pneumoniae and led to the formation of a membrane attack complex on S. pneumoniae (Fig. 6b). Because the same amount of $\beta C 3$ was used for fixation, the same amount of C3 was fixed on S. pneumoniae under all conditions. However, C3 activation was dominant only with the addition of SIGN-R1, demonstrating the 
(see figure on previous page)

Fig. 6 SIGN-R1-mediated C3 activation and opsonization of S. pneumoniae enhances the uptake and decomposition of the bacteria by SIGN-R1 ${ }^{+}$cells in vitro and in vivo. a Live S. pneumoniae type 14 (Pn14) was incubated with $5 \% \mathrm{NHS}$ at $37^{\circ} \mathrm{C}$ for 30 min in the presence of $10 \mu \mathrm{g}$ bovine serum albumin, transferrin (Tfe), or purified SIGN-R1, immunostained for C1q, and analyzed by FACS. b As in a, but $10 \mu \mathrm{g}$ Tfe or C1q was used, and organisms were immunostained for C1q, iC3b, or membrane attack complex (MAC). c As in a, but organisms were immunoblotted for C3. d In total, $1 \times 10^{8}$ mitomycin C-treated and PKH26-labeled S. pneumoniae (PKH26-MitC-Pn14) were incubated with CHO transfectants in the presence of $10 \mu \mathrm{g} \mathrm{C1q}$ or $5 \%$ NHS. The binding of organisms to cells was assessed by FACS. e DCEK_SIGN transfectants were incubated with MitC-Pn14 (1 $\times 10^{6}$, $15 \mathrm{~h}, 37^{\circ} \mathrm{C}$ ) without or with mouse sera (NMS or C3- or C1q-depleted mouse sera), and cells were immunostained for SIGN-R1 (green) or CPS14 (red), followed by microscopic analysis. Representative cells are shown in the boxes. $\mathbf{f}$ CFSE-MitC-Pn14 $\left(1 \times 10^{8}\right.$, green) were injected intravenously into control, SIGN-R1-KO, or C3-KO mice for $1 \mathrm{~h}$ and spleen sections were immunostained for SIGN-R1 (blue) and CPS14 (red). Representative areas in splenic MZs are highlighted in the boxes (middle row). Organisms captured in the red pulp (arrowheads) are highlighted (bottom row). Scale bars $\mathbf{e}$, $20 \mu \mathrm{m} ; \mathbf{f}, 50 \mu \mathrm{m}$

degradation of $\alpha \mathrm{C} 3$ and increased fixation of small iC3b (43 kDa; Fig. 6c).

With the addition of $\mathrm{C} 1 \mathrm{q}$ or normal human serum (NHS) as a source of $\mathrm{C} 1 \mathrm{q}$, pneumococcal binding was increased only on SIGN-R1 transfectants (Fig. 6d). Moreover, pneumococcal uptake and sequential decomposition were observed on SIGN-R1 transfectants only with normal mouse serum (NMS), but not without serum or with C3- or C1q-depleted sera (Fig. 6e and Supplementary Fig. S6a). After intravenous injection of $S$. pneumoniae into WT, SIGN-R1-KO, or C3-KO mice, pneumococcal uptake and cytoplasmic decomposition were obvious only on splenic MZ SIGN-R1 $1^{+}$macrophages from control mice (Fig. $6 \mathrm{f}$ and Supplementary Fig. S6b), but completely abolished in splenic MZs from SIGN-R1-KO and C3-KO mice and red pulp from all mice (Fig. 6f). The signal specificity of CPS14 on splenic MZ SIGN-R $1^{+}$macrophages of control mice in Fig. $6 \mathrm{f}$ was confirmed by immunostaining with its respective isotype control immunoglobulins (Supplementary Fig. S6c).

DC-SIGN may mediate the classical complement pathway in LRs from splenic MZ DC-SIGN ${ }^{+}$macrophages following S. pneumoniae challenge via interactions with $\mathrm{C} 1 \mathrm{q}$

When DC-SIGN transfectants were treated with S. pneumoniae, DC-SIGN aggregates were dramatically increased on the cell surface (Fig. 7a). Additionally, when LR fractions of these cells were immunoblotted for DCSIGN, monomers and dimers of DC-SIGN were obviously increased in LRs following $S$. pneumoniae challenge (Fig. 7b). Moreover, splenic MZ DC-SIGN ${ }^{+}$macrophages from DC-SIGN ${ }^{\mathrm{BMT}} / \mathrm{SIGN}-\mathrm{R} 1^{\mathrm{TKO}}$ mice recovered the rapid recognition of $S$. pneumoniae on splenic MZs, even at $15 \mathrm{~min}$ and $1 \mathrm{~h}$ after intravenous injection of the organisms (Fig. 7c). In spleens at $1 \mathrm{~h}, \mathrm{DC}-\mathrm{SIGN}$ monomers and multimers were obviously upregulated only in splenic LRs following S. pneumoniae challenge (Fig. 7d).

DC-SIGN bound well to purified human C1q or human C1q from NHS (Fig. 7e). Additionally, DC-SIGN binding to mouse C1q from NMS was confirmed by immunoblotting and immunostaining (Fig. 7e and Supplementary
Fig. S7a). We then examined whether DC-SIGN bound directly to C4, similar to SIGN-R $1^{39}$ (Supplementary Fig. S4a). DC-SIGN transfectants showed clear fixation of C4 (Fig. 7f). Additionally, DC-SIGN-transfected HEK293T cells also induced the fixation of C1q or C4 from NHS, confirming again the binding of DC-SIGN to $\mathrm{C} 1 \mathrm{q}$ and $\mathrm{C} 4$ (Fig. $7 \mathrm{~g}$ ), and their fixation was significantly increased following S. pneumoniae challenge (Fig. $7 \mathrm{~g}$ ).

In splenic fractions from DC-SIGN ${ }^{\mathrm{BMT}} / \mathrm{SIGN}-\mathrm{R} 1^{\mathrm{TKO}}$ mice, upregulation of $\mathrm{C} 1 \mathrm{q}$ and $\mathrm{C} 4$ was obvious following S. pneumoniae challenge (Fig. 7h). Moreover, after intravenous injection of $S$. pneumoniae into DC-SIGN ${ }^{\mathrm{BMT}}$ / SIGN-R1 $1^{\text {TKO }}$ mice, systemic $\mathrm{C} 3$ activation reappeared in SIGN-R1 $1^{\text {TKO }}$ mice as in control mice, demonstrating gradual decrease in $\alpha \mathrm{C} 3$ and larger $\mathrm{iC} 3 \mathrm{~b}$ and a rapid increase and sequential decrease in small iC3b (Fig. 7i). C3 fixation was also completely recovered around splenic $\mathrm{MZ} \mathrm{DC-SIGN}^{+}$macrophages in DC-SIGN ${ }^{\mathrm{BMT}} / \mathrm{SIGN}$ $\mathrm{R} 1^{\mathrm{TKO}}$ mice from SIGN-R1-KO or SIGN-R1 ${ }^{\mathrm{TKO}}$ mice as in control mice (Fig. 7j and Supplementary Fig. S7b), occurring rapidly within $15 \mathrm{~min}$ after challenge with $S$. pneumoniae and disappearing at $4 \mathrm{~h}$ (Supplementary Fig. S7c). Immunostaining with isotype control IgG for antiC3 antibodies did not yield a C3 signal (Supplementary Fig. S7d). Moreover, immunoblotting of cadaver spleens for $\mathrm{C} 1 \mathrm{q}, \mathrm{C} 4$, and $\mathrm{C} 3$ revealed expression in human splenic LRs, with predominant expression of $\mathrm{C} 1 \mathrm{q}$ and $104-\mathrm{kDa}$ $\alpha C 3^{\prime}$ rather than $113-k D a \alpha C 3$ (Fig. 7k and Supplementary Fig. S7e).

\section{Discussion}

Although DC-SIGN and SIGN-R1 professionally recognize and remove S. pneumonia ${ }^{35,41}$, the disruption of LRs on both lectin transfectants resulted in serious impairment of the uptake and sequential decomposition of the organism. Because the disruption of LRs did not alter the expression levels of both lectins on the respective transfectants, which would lead to normal binding of the organism to the cell surface, the structure of LRs may be more important for the function of both lectins and for removal of S. pneumoniae than previously thought. This 


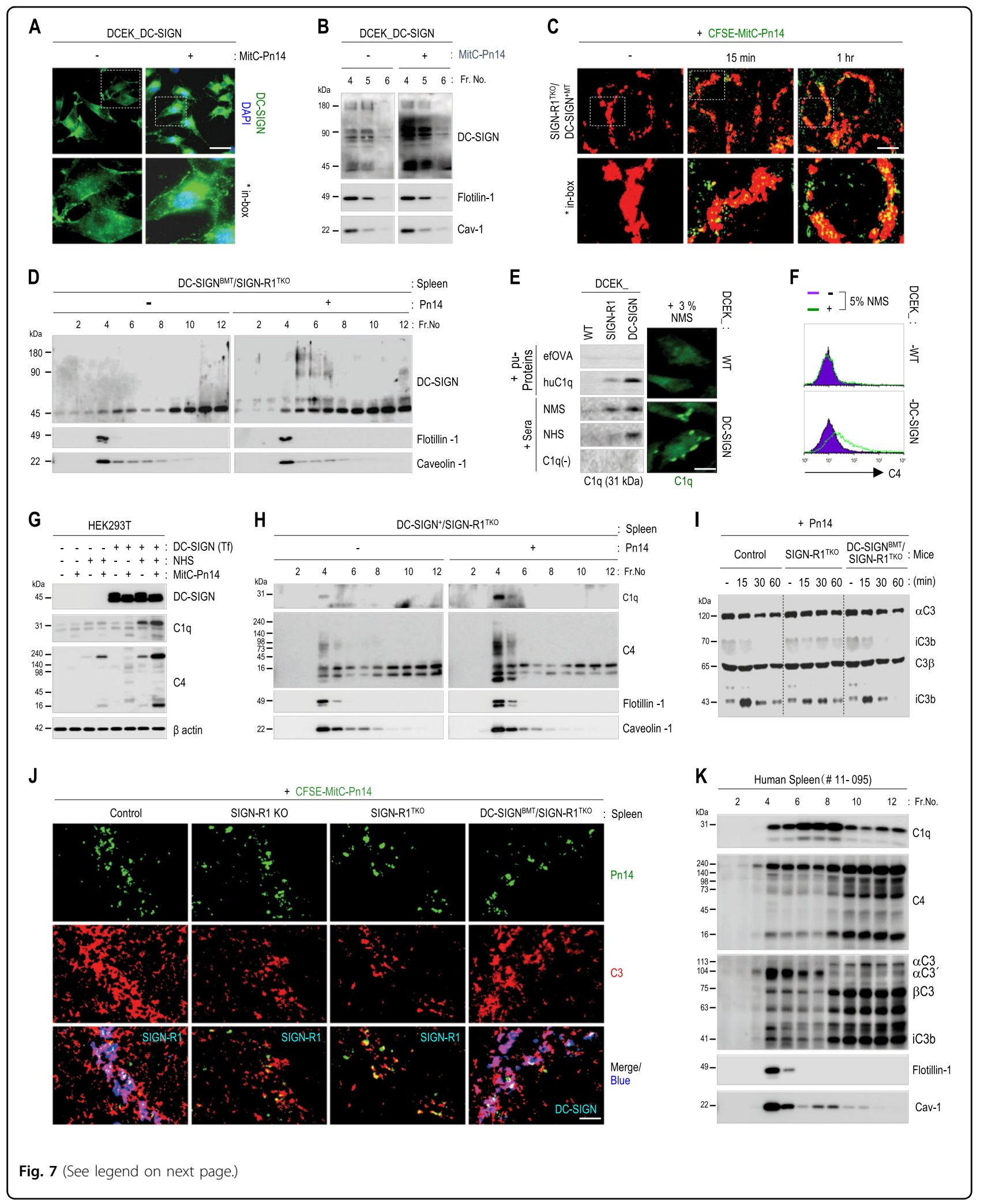


(see figure on previous page)

Fig. 7 DC-SIGN in splenic lipid rafts may mediate the classical complement pathway in response to $S$. pneumoniae challenge by interacting with C1q and C4. a DCEK_DC-SIGN transfectants were incubated with mitomycin C-treated S. pneumoniae type 14 (MitC-Pn14; $1 \times 10^{6}, 15$ min, $37^{\circ} \mathrm{C}$ ) and immunostained for DC-SIGN without permeabilization. A representative cell is shown in the box. $\mathbf{b}$ After DCEK_DC-SIGN transfectants were incubated with MitC-Pn14 $\left(1 \times 10^{6}, 1 \mathrm{~h}, 37^{\circ} \mathrm{C}\right)$, lysates were fractionated with sucrose gradient ultracentrifugation, and fractions of LRs were immunoblotted for DC-SIGN, flotilin-1, or caveolin-1. c DC-SIGN ${ }^{\text {BMT }} / \mathrm{SIGN}-\mathrm{R} 1^{\text {TKO }}$ mice were injected intravenously with CFSE-labeled MitC-Pn14 (green; $1 \times 10^{8}, 15 \mathrm{~min}$ or $1 \mathrm{~h}$ ), and splenic sections were immunostained for DC-SIGN (red). $\mathbf{d}$ As in $\mathbf{b}$, but spleens of DC-SIGN ${ }^{\text {BMT }} /$ SIGN-R $^{\text {TKO }}$ mice were used after intravenous injection of live S. pneumoniae $\left(1 \times 10^{8}, 1 \mathrm{~h}\right.$ ). e (Left) Wild-type or DCEK transfectants were incubated with $5 \mu \mathrm{g}$ endotoxin-free ovalbumin (efOVA), human C1q, or 3\% sera (NMS, NHS, or C1q-depleted human serum) in TC buffer for $1 \mathrm{~h}$ at $37^{\circ} \mathrm{C}$, and lysates were immunoblotted for C1q. (Right) Wild-type or DCEK_DC-SIGN transfectants were incubated with $3 \% \mathrm{NMS}$ for $1 \mathrm{~h}$ at $37^{\circ} \mathrm{C}$ and immunostained for C1q, followed by microscopic analysis. Representative areas are highlighted from low-power images in Figure S7a. f Wild-type or DCEK transfectants were incubated with $5 \%$ NMS for $10 \mathrm{~min}$ at $37^{\circ} \mathrm{C}$, immunostained for C4 without permeabilization, and analyzed by FACS. $\mathbf{g}$ Empty vector or DC-SIGN-transfected HEK293T cells were incubated without or with MitC-Pn14 $\left(1 \times 10^{7}\right)$ in the absence or presence of $5 \% \mathrm{NHS}$ for 15 min at $37^{\circ} \mathrm{C}$, and cell lysates were immunoblotted for DC-SIGN, C1q, C4, and $\beta$-actin. $\mathbf{h}$ As in $\mathbf{d}$, but DC-SIGN ${ }^{\text {BMT }} /$ SIGN-R1 $1^{\text {TKO }}$ mice were used, and splenic fractions were immunoblotted for C1q or C4. i Control, SIGN-R1 ${ }^{\text {TKO }}$, and DC-SIGN ${ }^{\text {BMT }} / \mathrm{SIGN}-\mathrm{R} 1^{\text {TKO }}$ mice were injected intravenously with Pn14 $\left(1 \times 10^{8}\right)$, and their sera were collected at 0, 15, 30, or 60 min and immunoblotted for C3. j As in c, but control, SIGN-R1 KO, SIGN-R1 ${ }^{\text {TKO }}$, and DC-SIGN ${ }^{\text {BMT }} /$ SIGN-R1 $^{\text {TKO }}$ mice were intravenously injected for $15 \mathrm{~min}$. Splenic sections were immunostained for C3 (red) and SIGN-R1 (green) or C3 (red) and DC-SIGN (green). Representative areas are highlighted from low-power images in Figure S7b. $\mathbf{k}$ As in $\mathbf{h}$, but spleens of cadavers were used and immunoblotted for C1q, C4, and C3. Representative data are presented from the results of four cadavers. Scale bars $\mathbf{a}, \mathbf{e}, 20 \mu \mathrm{m} ; \mathbf{c}, 250 \mu \mathrm{m} ; \mathbf{j}, 50 \mu \mathrm{m}$

speculation was strongly supported by the following results. First, multimers of DC-SIGN or SIGN-R1 were preformed in LRs of the respective transfectants, and even SIGN-R1 multimers were preformed in splenic LRs. Additionally, DC-SIGN and SIGN-R1 multimers were increased only in LRs following S. pneumoniae challenge in vitro or in vivo, but not in non-LRs. Therefore, LRs could provide a spatially confined and optimal platform for DC-SIGN and SIGN-R1 to facilitate clustering, increase their affinity and specificity to pathogens, and enhance their clearance, thus affecting their innate protective functions ${ }^{7,45}$.

Raft locations for target antigens favor classical complement activation by concentrating the antigen-antibody complex into a comparatively small area, thus providing an ideal density for juxtaposed Fc regions to engage $\mathrm{C} 1 \mathrm{q}^{46,47}$. Similarly, both $\mathrm{C} 1 \mathrm{q}$ and $\mathrm{C} 4$ were exclusively distributed in splenic LRs among fractions from examined mouse tissues, showing a significant dependence on the existence of SIGN-R1. SIGN-R1 was exclusively expressed on splenic MZ macrophages ${ }^{42}$ and bound directly to $\mathrm{Clq}$ or $\mathrm{C}^{39,48}$. Additionally, there is a potential interaction between $\mathrm{C} 1 \mathrm{q}$ and $\mathrm{C}_{4}^{49,50}$. Therefore, their exclusive distribution in splenic LRs is expected, and these proteins may be further subdivided into splenic MZ SIGN-R1 ${ }^{+}$ LRs from heterogeneous LRs of various splenic cells ${ }^{51}$. These findings suggested that splenic MZ SIGN-R $1^{+}$LRs may provide optimal microenvironmental platforms for reciprocal interactions among SIGN-R1, C1q, and C4, thus preforming a trimolecular complex to rapidly activate the SIGN-R1-mediated classical complement pathway in the spleen.

Because SIGN-R1 or C1q directly recognize S. pneumoniae $^{41,52}$, the preformed trimolecular complex of SIGN-R1, C1q, and C4 in splenic MZ SIGN-R1 ${ }^{+}$LRs could accelerate the generation of a classical pathway $\mathrm{C} 3$ convertase $(\mathrm{C} 4 \mathrm{bC} 2 \mathrm{a})$, and the resulting abundant $\mathrm{C} 4 \mathrm{~b}$ and $\mathrm{C} 4 \mathrm{bC} 2 \mathrm{a}$ could sequentially promote fixation of $\mathrm{C} 3$ on the cell surface ${ }^{53-56}$. Supporting this possibility, C3, particularly C3 $\alpha$, was most enriched in splenic LRs, despite having lowest expression in the spleen among examined mouse tissues. Therefore, splenic MZ SIGN-R1 $1^{+}$LRs may be optimized to activate $\mathrm{C} 3$, although the $\mathrm{C} 3$ distribution was independent of the existence of SIGN-R1, probably due to covalent fixation of $\mathrm{C} 3$ fragments on other splenic cells $^{57}$. Because the complement system should be tightly controlled under physiological conditions to prevent significant damage to self-tissues, enrichment of SIGN-R1, C1q, C4, and C3 in splenic MZ SIGN-R1 ${ }^{+}$LRs could also precisely regulate complement activation in splenic MZs; indeed, nascent $\mathrm{C} 3 \mathrm{~b}$ and $\mathrm{C} 4$ regulate $\mathrm{C} 1$ activation in concert with $\mathrm{C} 3$ under normal conditions ${ }^{58}$.

Pneumococcal challenge increased both $\mathrm{C} 1 \mathrm{q}$ and $\mathrm{C} 4$ and activated C3 only in splenic MZ SIGN-R $1^{+}$LRs without the involvement of other complement pathways. Therefore, splenic MZ SIGN-R1 ${ }^{+}$LRs may provide optimal locations for SIGN-R1-mediated C3 activation to accelerate pneumococcal clearance by sequentially enhancing pneumococcal iC3b opsonization and rapid phagocytosis primarily in splenic MZ SIGN-R1 ${ }^{+}$macrophages. In particular, S. pneumoniae capsules inhibit its recognition by natural IgM, the binding of the serum proteins to subcapsular targets, complement activity, and neutrophil phagocytosi ${ }^{59,60}$. However, enrichment of SIGN-R1, C1q, C4, and C3 in splenic MZ SIGN-R1 ${ }^{+}$LRs could dramatically enhance the simultaneous recognition of pneumococcal CPSs with SIGN-R1 and C1q, thus overcoming impairment of the initial pneumococcal recognition ${ }^{61}$.

The human spleen and the classical pathway are integral for protection against infection by S. pneumoniae $e^{39,62-65}$. 
In particular, the DC-SIGN-C1q complex could also mediate a classical complement pathway against $S$. pneumoniae in the spleen, representing a potential protection mechanism in the human spleen ${ }^{24}$. Indeed, the replaced DC-SIGN on splenic MZs of DC-SIGN ${ }^{\mathrm{BMT}}$ / SIGN-R1 ${ }^{\mathrm{TKO}}$ mice completely rescued the pneumococcal capture, the sequential activation and deposition of $\mathrm{C} 3$ against S. pneumoniae in splenic MZs, which was likely to be related to the DC-SIGN-induced complex of mouse $\mathrm{C} 1 \mathrm{q}$ and $\mathrm{C} 4$. Previous studies have shown that recruitment of DC-SIGN into LRs with binding to viral glycoproteins or the $\mathrm{gC} 1 \mathrm{qR}^{29,31,66}$ strengthens the possible formation of a tetramolecular complex of glycoproteins/ DC-SIGN/C1q/gC1qR and thus increases binding capacity through the complex ${ }^{24,67}$. Therefore, similar to SIGNR1, splenic MZ DC-SIGN ${ }^{+}$LRs may also provide a favorable microenvironment for the DC-SIGN-mediated classical complement pathway by forming another tetramolecular complex of DC-SIGN, C1q, gC1qR, and C4, finally enhancing sequential $\mathrm{C} 3$ activation.

Because DC-SIGN is exclusively expressed on human splenic perifollicular zone macrophages ${ }^{37}$, the presence of DC-SIGN in cadaver splenic LRs indicates that DC-SIGN is expressed in LRs from human splenic perifollicular zone macrophages. Also, similar with the previous reports $^{32,68,69}$, complements $\mathrm{C} 1 \mathrm{q}, \mathrm{C} 4$, and $\mathrm{C} 3 \mathrm{~b}$ were enriched in human splenic LRs. Therefore, these cadaver splenic perifollicular zone DC-SIGN ${ }^{+}$LRs may also be important for the DC-SIGN-mediated classical complement system against $S$. pneumoniae, explaining why the spleen and the classical pathway are integral for protection against infections to S. pneumoniae in humans ${ }^{63-65}$.

The importance of LRs has been restricted to their roles in receptor-mediated intracellular events from the plasma membrane, so far. However, splenic MZ LRs provide bidirectional platforms not only for usual events associated with the intracellular milieu, for example, recognition and phagocytosis of pathogens in vivo, but also unusual events associated with the extracellular milieu, such as the complement system, orchestrating early and complicated host responses to microbial infection. Thus, the spleen could be equipped with the most sensitive system to target various pathogens, such as S. pneumoniae ${ }^{35,36}$ and human immunodeficiency virus- $1^{37,38}$. These findings can explain how such a small portion of splenic SIGN-R1 ${ }^{+}$macrophages $(<0.05 \%)$ helps the spleen to efficiently protect hosts against $S$. pneumoniae, providing insights into the involvement of LRs in the innate immune system and the roles of DC-SIGN in the human spleen.

\section{Materials and methods \\ Bacterial strains}

Streptococcus pneumoniae capsular serotype 14 (DCC1490), the unencapsulated S. pneumoniae Tn916 mutant Spn14.H, and Staphylococcus aureus strain (RN4220) were used, all of which were kindly provided by Professor Vincent A. Fischetti of Rockefeller University (New York, USA).

\section{Cell culture}

DCEK, a mouse L-cell fibroblast line, and human embryonic kidney (HEK293T) cells were cultured in RPMI-1640 medium, and CHO cells were cultured in Dulbecco's modified Eagle's medium, supplemented with $10 \%$ fetal bovine serum, $100 \mathrm{U} / \mathrm{mL}$ penicillin G, and $100 \mathrm{mg} / \mathrm{mL}$ streptomycin. Stable DCEK transfectants expressing complementary (cDNA) for DC-SIGN or SIGN-R1 (DCEK_DC-SIGNS and DCEK_SIGN-R1 in the figures, respectively) and stable $\mathrm{CHO}$ transfectants expressing cDNA for Neo, or SIGN-R1 (CHO_Neo, or CHO_SIGN-R1 in the figures, respectively) were used.

\section{In vivo animal studies}

Female C57BL/6 mice (6-10 weeks old, weighing 16-20 g) were purchased (The Jackson Laboratory, Bar Harbor, ME, USA) and housed under specific pathogen-free conditions. SIGN-R1 (CD209b)-KO mice were kindly provided by the Consortium for Functional Glycomics (http:// www.functionalglycomics.org). DC-SIGN transgenic donor mice were provided by the Rockefeller Gene Targeting Resource Center and identified by PCR using DC-SIGN gene primers forward (5'-CgggATCCgAgTggggTgACA TgAgTgACT-3') and reverse (5'-ACgCgTCgACAAA AgggggTgAAgTTCTgCTACg- $\left.3^{\prime}\right)$. For in vivo experiments using animal models, all studies were approved by the Institutional Animal Care and Use Committee of Konkuk University (permit number: KU11107) and performed in strict accordance with the approved guidelines for animal care and animal experimentation. Animal welfare was overseen by local committees. Mice were housed in a temperature-controlled room with an automated darkness-light cycle system and had ad libitum access to food and water. Mice were challenged with $1 \times 10^{8}$ colonyforming unit of S. pneumoniae suspended in $100 \mathrm{~mL}$ of PBS in PBS intravenously. Prior to tissue dissection, the mice were sacrificed via euthanasia using an overdose of $\mathrm{CO}_{2}$ with a flow rate $20 \%$ of the cage volume per minute, following AVMA Guidelines for the Euthanasia of Animals.

\section{Bacterial growth conditions and fluorescent labeling}

Streptococcus pneumoniae capsular serotype 14 (DCC1490), the unencapsulated S. pneumoniae Tn916 mutant Spn14.H (mt-Pn14), and Staphylococcus aureus were grown in brain heart infusion broth (DIFCO) to mid-logarithmic phase $\left(18 \mathrm{~h}, 37^{\circ} \mathrm{C}\right)$. Bacteria were inactivated with $50 \mu \mathrm{g} / \mathrm{mL}$ mitomycin C (Sigma) for $1 \mathrm{~h}$ and suspensions of $10^{9}$ bacteria were labeled with PKH26 following the manufacturer's instructions or with $5 \mathrm{mM}$ 
CFSE (Sigma-Aldrich) for $30 \mathrm{~min}$ at $37^{\circ} \mathrm{C}$. The fluorescent bacteria were injected intravenously into mice or incubated with cells.

\section{Cellular and tissue immunofluorescence microscopy}

Cells on coverslips or $10 \mu \mathrm{m}$ OCT (Tissue-Tek) frozen spleen sections were fixed with $100 \%$ acetone $(10 \mathrm{~min}$, room temperature) and stained, where indicated, with DAPI (4',6-diamidino-2-phenylindole) (blue) or FITC-, PE-, AMCA-, or Alexa Fluor-conjugated donkey antichicken IgY, goat anti-hamster IgG, donkey anti-rabbit IgG, goat anti-rat IgG, and streptavidin as secondary reagents (purchased from Abcam, Jackson ImmunoResearch Laboratories, or Molecular Probes). Cells and spleen sections were examined for fluorescence with a deconvolution fluorescence BX61-32FDIC microscope (Olympus Corp., Tokyo, Japan). Images were acquired with a Coolsnap ${ }^{E Z}$ system (Roper Scientific, Inc., AZ, USA).

\section{Flow cytometry}

Cells used in FACS analysis were detached with $1 \mathrm{mM}$ EDTA in PBS for $10 \mathrm{~min}$ and pre-incubated $10 \mathrm{~min}$ with 2.4G2 monoclonal antibody at $4{ }^{\circ} \mathrm{C}$ to block Fc receptors. Cells or S. pneumoniae were incubated with 3-5\% mouse or human serum in $200 \mu \mathrm{L}$ TC buffer $(10 \mathrm{mM}$ Tris- $\mathrm{HCl}$, $140 \mathrm{mM} \mathrm{NaCl}, 2 \mathrm{mM} \mathrm{CaCl}_{2}, 2 \mathrm{mM} \mathrm{MgCl}$, and $1 \%$ bovine serum albumin [BSA]), and complement binding to cells or organisms was detected by immunostaining with respective antibodies for $30 \mathrm{~min}$ at $4{ }^{\circ} \mathrm{C}$. Cytometric analysis was performed using a FACScan (Becton Dickinson, San Jose, CA, USA) and CellQuestPro (BD Biosciences). Subsequent data analysis was performed with CellQuestPro (BD Biosciences).

\section{Streptococcus pneumoniae uptake and decomposition analysis in vitro and in vivo}

Cells $\left(1 \times 10^{5}\right)$ were incubated with mitomycin C-treated and CFSE-labeled S. pneumoniae $\left(1 \times 10^{6}\right)$ for the indicated times at $37^{\circ} \mathrm{C}$, and bacterial binding to cells and cytoplasmic decomposition of capsular polysaccharides of $S$. pneumoniae were examined with a fluorescence microscope. Mice were intravenously injected with mitomycin C-treated and CFSE-labeled S. pneumoniae $\left(1 \times 10^{8}\right)$ for the indicated times ${ }^{39,41}$, and bacterial binding and decomposition were examined on SIGN-R1 ${ }^{-}$or SIGN-R1 ${ }^{+}$cells of spleen tissues.

\section{Quantification of bacterial decomposition ratios}

To quantify the pneumococcal decomposition ratio, the number of pneumococcal-bound or -decomposing cells was counted, and the average percentage of pneumococcal-decomposing cells from the total number of pneumococcal-bound cells was calculated in five areas for each sample from five independent experiments.

\section{Cell fractionation and purification of LRs with sucrose gradients}

Tissues from mice or cells were solubilized in $2 \mathrm{~mL}$ of 1\% Triton X-100 (Junsei Chemical Co., Ltd.) in MESbuffered saline (MBS, $25 \mathrm{mM}$ MES, pH 6.5, $150 \mathrm{mM}$ $\mathrm{NaCl})$. After homogenizing with 10 up-and-down strokes of a tight-fitting Dounce homogenizer, the tissue or cellular extracts were adjusted to $4 \mathrm{~mL}$ with sucrose concentrations of $45 \%$ or $40 \%$, respectively, and overlaid with $4 \mathrm{~mL}$ of $30 \%$ sucrose and $4 \mathrm{~mL}$ of $5 \%$ sucrose in MBS. The sucrose gradient was formed by centrifugation at $200,000 \times$ g for $18-20 \mathrm{~h}$ at $4{ }^{\circ} \mathrm{C}$ using a Beckman SW $41 \mathrm{ti}$ rotor. After centrifugation, the sucrose gradients were fractionated into 12 fractions without pelleting, and an opaque buoyant band corresponding to the LRs was collected at the interface between the $30 \%$ and $5 \%$ sucrose gradients. The same quantity of proteins from each fraction was used for immunoblotting analysis.

\section{Plasmids and transfection}

Clone pMX DC-SIGN was a gift from Dr. Chae Gyu Park (Rockefeller University). This clone c DC-SIGN expression was monitored by immunoblotting analysis using anti-DC-SIGN antibodies. DCEK transfectants were transiently transfected with plasmids encoding dynamin II K44A (dominant-negative dynamin with a point mutation in the nucleotide-binding site, a gift from Professor Seung-Jae Lee, Seoul National University College of Medicine, Seoul, Korea) or with an empty pcDNA3 vector for $48 \mathrm{~h}$, using Lipofectamine Plus reagent (Invitrogen Life Technologies, Carlsbad, CA, USA) according to the manufacturer's specifications.

\section{SIGN-R1 TKO mouse generation}

SIGN-R1 TKO or isotype control mice were generated by intravenous injection of $100 \mu \mathrm{g} 22 \mathrm{D} 1$ antibody or isotype hamster IgG for $48 \mathrm{~h}$. The 22D1 antibody selectively and transiently depleted the surface SIGN-R1 molecule, but not SIGN-R1 $1^{+}$macrophages in the splenic MZ, permitting analysis of its function in vivo, as in a previous report $^{70}$.

\section{DC-SIGN transgenic mouse generation}

DC-SIGN transgenic (DC-SIGN ${ }^{\mathrm{BMT}} / \mathrm{WT}$ ) mice were generated from the reconstitution of lethally irradiated C57BL/6 mice with bone marrow cells of DC-SIGN transgenic donor mice. SIGN-R1-depleted DC-SIGN transgenic (DC-SIGN ${ }^{\mathrm{BMT}} / \mathrm{SIGN}-\mathrm{R} 1^{\mathrm{TKO}}$ ) mice were generated from the intravenous injection of 22D1 for $48 \mathrm{~h}$ into DC-SIGN ${ }^{\mathrm{BMT}} / \mathrm{WT}$ mice. 


\section{Complement C3-depleted mice}

Control mice were obtained by intraperitoneally injecting $60 \mathrm{U} / \mathrm{kg}$ of cobra venom factor one day prior to the experimental challenge. C3 depletion was confirmed by Western blot analysis for $\mathrm{C} 3$ by using sera.

\section{Mouse infection studies}

Mitomycin C-treated fluorescent bacteria $\left(1 \times 10^{8}\right)$ were intravenously administered to mice for the indicated times. Mice were sacrificed, and spleen sections were examined by deconvolution fluorescence microscopy.

\section{Assay for in vivo and in vitro $\mathrm{C} 3$ processing}

To quantify C3 processing in tissues in vivo, $1 \times 10^{8}$ S. pneumoniae were injected intravenously, and tissue lysates were collected at the indicated times, separated by sodium dodecyl sulfate polyacrylamide gel electrophoresis (SDS-PAGE), and immunoblotted with polyclonal antimouse $\mathrm{C} 3$ antibodies. For in vitro $\mathrm{C} 3$ processing, $1 \times 10^{8}$ S. pneumoniae were incubated with $5 \%$ NHS in TC buffer ( $140 \mathrm{mM} \mathrm{NaCl}, 2 \mathrm{mM} \mathrm{CaCl}, 2 \mathrm{mM} \mathrm{MgCl}_{2}, 10 \mathrm{mM}$ Tris, $\mathrm{pH} 7.5$, supplemented with $1 \% \mathrm{BSA}$ ) for $30 \mathrm{~min}$ at $37^{\circ} \mathrm{C}$. The bacteria were washed, mixed, and boiled with $20 \mu \mathrm{L}$ of $2 \times$ SDS sample buffer. Bacterial lysates were separated by SDS-PAGE and immunoblotted with polyclonal antimouse $\mathrm{C} 3$ antibodies. These antibodies detected the components of native $\mathrm{C} 3, \alpha \mathrm{C} 3$, and $\beta \mathrm{C} 3$, as well as the fragments of $\alpha \mathrm{C} 3$ (molecular weights in humans: $113 \mathrm{kDa}$ for $\alpha \mathrm{C} 3,104 \mathrm{kDa}$ of $\alpha \mathrm{C3}^{\prime}, 63 \mathrm{kDa}$ and $41 \mathrm{kDa}$ for iC3b fragments, and $75 \mathrm{kDa}$ for $\beta C 3$; molecular weights in rats: $120 \mathrm{kDa}$ for $\alpha \mathrm{C} 3,70 \mathrm{kDa}$ and $43 \mathrm{kDa}$ for iC3b fragments, and $65 \mathrm{kDa}$ for $\beta \mathrm{C} 3$ ) that are generated during $\mathrm{C} 3$ processing by $\mathrm{C} 3$ convertases by immunoblotting analysis. In the steady state, $\alpha \mathrm{C} 3$ and $\beta C 3$ are predominant, with a few larger iC3b. With activation, $\alpha \mathrm{C} 3$ and larger iC3b are rapidly processed into smaller fragments, including $43 \mathrm{kDa} \mathrm{iC} 3 \mathrm{~b}$, but not $\beta \mathrm{C} 3$, which serves as a loading control for the immunoblotting analysis, resulting in loss of most of the detectable $\alpha \mathrm{C} 3$ as well as larger iC3b, but accumulation of the smaller $\mathrm{iC} 3 \mathrm{~b}$ in $\mathrm{C} 3$ activation in immunoblotting analysis ${ }^{70}$.

\section{Western blot analysis and immunodetection}

Tissues, cells, and bacteria were lysed in RIPA buffer (150 mM NaCl, 50 mM Tris- $\mathrm{HCl}, \mathrm{pH}$ 8.0/1\% Nonidet P$40 / 0.5 \%$ sodium deoxycholate $/ 0.1 \%$ SDS) supplemented with $0.2 \%$ protease inhibitor cocktail (Sigma), and lysed samples were mixed with an equal volume of $2 \times$ SDS sample buffer containing 2-mercaptoethanol and boiled at $95^{\circ} \mathrm{C}$ for $5 \mathrm{~min}\left(100^{\circ} \mathrm{C}\right.$ for $\left.10 \mathrm{~min}\right)$. Diluted sera (1:50) or fractions of LRs were mixed with $2 \times$ or $5 \times$ SDS sample buffer with 2-mercaptoethanol and boiled at $95^{\circ} \mathrm{C}$ for $10 \mathrm{~min}\left(100^{\circ} \mathrm{C}\right.$ for $\left.10 \mathrm{~min}\right)$. The samples were separated by SDS-PAGE on $4-15 \%$ gradient gels and transferred to polyvinylidene difluoride membranes, followed by incubation with antibodies. Antibody-reactive bands on the blots were visualized with peroxidase-labeled secondary antibodies, followed by treatment with West-ZOL plus (Intron) or Immobilon (Millipore).

\section{Human cadaver spleen studies}

Human cadaveric spleens were donated from the Department of Anatomy, School of Medicine, Konkuk University (Seoul, Korea).

\section{Software used in this study}

Fluorescent images were analyzed with the MetaMorph software (Universal Imaging). Immunoblotting signals were detected using LAS-4200 (Fuji Film).

\section{Statistical analyses}

The number of cells binding to bacteria and the number of cells decomposing bacteria were counted. The average percentage of pneumococcal decomposition of the total pneumococcal binding to cells was calculated in five areas of each sample from three independent experiments and shown in the indicated graphs. Data are presented as mean \pm SD. Statistical significance between groups were determined by two-way analysis of variance, followed by Tukey's post hoc tests and unpaired Student's $t$ tests with a two-tailed test. $p$ Value $<0.05$ was taken to indicate statistical significance (not significant, ns; $" p<0.05$; $" * p<0.01 ; * * * 0<0.001)$

\section{Acknowledgements \\ This work was supported by the Basic Science Research Program through the National Research Foundation of Korea (NRF) funded by the Ministry of Education, Science, and Technology (S201803S00049); Health Technology R \& D Project through the Korea Health Industry Development Institute (KHIDI), Ministry of Health \& Welfare, Republic of Korea (HI17C1713); and Basic Science Research Program through the National Research Foundation of Korea (NRF) funded by the Ministry of Science, ICT \& Future Planning (NRF2017R1C1B2010487).}

\begin{abstract}
Author details
'Department of Biomedical Science and Technology, Konkuk University, 1 Hwayang-dong, Gwangjin-gu, Seoul 143-701, Republic of Korea. ${ }^{2}$ Department of Obstetrics and Gynecology, Division of Maternal and Fetal Medicine, Research Institute of Medical Science, Konkuk University School of Medicine, 120 Neungdong-ro, Gwangjin-gu, Seoul 05029, Korea. ${ }^{3}$ Department of Anatomy, Research Institute of Medical Science, Konkuk University School of Medicine, 120 Neungdong-ro, Gwangjin-gu, Seoul 05029, Korea. ${ }^{4}$ Department of Oncology, Georgetown University Medical Center, Washington, DC, USA. ${ }^{5}$ Department of Pathology, New York University School of Medicine, New York, NY 10016, USA. 'aboratory Animal Center, KBIO Health, Osongsarngmyon-ro 123, Ghungju-si, Chungbuk, Korea. 'Department of Veterinary Pharmacology and Toxicology, Veterinary Science Research Institute, College of Veterinary Medicine, Konkuk University, 120 Neungdong-ro, Gwangjin-gu, Seoul 05029, Korea. ${ }^{8}$ Department of Infectious Diseases, College of Veterinary Medicine,
\end{abstract} Konkuk University, 120 Neungdong-ro, Gwangjin-gu, Seoul 05029, Korea

Conflict of interest

The authors declare that they have no conflict of interest. 


\section{Publisher's note}

Springer Nature remains neutral with regard to jurisdictional claims in published maps and institutional affiliations.

The online version of this article (https://doi.org/10.1038/s41420-019-0213-3) contains supplementary material, which is available to authorized users.

Received: 5 April 2019 Revised: 11 July 2019 Accepted: 18 August 2019 Published online: 09 September 2019

\section{References}

1. Simons, K. \& Toomre, D. Lipid rafts and signal transduction. Nat. Rev. Mol. Cell. Biol. 1, 31-39 (2000)

2. Vieira, F. S., Correa, G., Einicker-Lamas, M. \& Coutinho-Silva, R. Host-cell lipid rafts: a safe door for micro-organisms? Biol. Cell 102, 391-407 (2010).

3. Rosenberger, C. M., Brumell, J. H. \& Finlay, B. B. Microbial pathogenesis: lipid rafts as pathogen portals. Curr. Biol. 10, R823-R825 (2000)

4. Manes, S., del Real, G. \& Martinez, A. C. Pathogens: raft hijackers. Nat. Rev Immunol. 3, 557-568 (2003).

5. Simons, K. \& Sampaio, J. L. Membrane organization and lipid rafts. Cold Spring Harb. Perspect. Biol. 3, a004697 (2011)

6. Head, B. P., Patel, H. H. \& Insel, P. A. Interaction of membrane/lipid rafts with the cytoskeleton: impact on signaling and function: membrane/lipid rafts, mediators of cytoskeletal arrangement and cell signaling. Biochim. Biophys. Acta 1838, 532-545 (2014).

7. Triantafilou, M., Miyake, K., Golenbock, D. T. \& Triantafilou, K. Mediators of innate immune recognition of bacteria concentrate in lipid rafts and facilitate lipopolysaccharide-induced cell activation. J. Cell Sci. 115, 2603-2611 (2002).

8. Harder, T. Lipid raft domains and protein networks in T-cell receptor signal transduction. Curr. Opin. Immunol. 16, 353-359 (2004).

9. Triantafilou, M., Lepper, P. M., Olden, R., Dias, I. S. \& Triantafilou, K. Location, location, location: is membrane partitioning everything when it comes to innate immune activation? Mediat. Inflamm. 2011, 186093 (2011).

10. Varshney, P., Yadav, V. \& Saini, N. Lipid rafts in immune signalling: current progress and future perspective. Immunology 149, 13-24 (2016).

11. Rus, H., Cudrici, C. \& Niculescu, F. The role of the complement system in innate immunity. Immunol. Res. 33, 103-112 (2005).

12. Fujita, T. Evolution of the lectin-complement pathway and its role in innate immunity. Nat. Rev. Immunol. 2, 346-353 (2002).

13. Walport, M. J. Complement. First of two parts. N. Engl. J. Med. 344, 1058-1066 (2001).

14. Kemper, C. \& Atkinson, J. P. T-cell regulation: with complements from innate immunity. Nat. Rev. Immunol. 7, 9-18 (2007).

15. Kemper, C. \& Kohl, J. Novel roles for complement receptors in T cell regulation and beyond. Mol. Immunol. 56, 181-190 (2013).

16. Jones, C. L. et al. Subversion of host recognition and defense systems by Francisella spp. Microbiol. Mol. Biol. Rev. 76, 383-404 (2012).

17. Aman, M. J., Tosello-Trampont, A. C. \& Ravichandran, K. Fc gamma RIIB1/SHIPmediated inhibitory signaling in B cells involves lipid rafts. J. Biol. Chem. 276, 46371-46378 (2001)

18. Lang, M. L. et al. IgA Fc receptor (FcalphaR) cross-linking recruits tyrosine kinases, phosphoinositide kinases and serine/threonine kinases to glycolipid rafts. Biochem. J. 364, 517-525 (2002).

19. Vereb, G. et al. Cholesterol-dependent clustering of IL-2Ralpha and its colocalization with HLA and CD48 on T lymphoma cells suggest their functional association with lipid rafts. Proc. Natl Acad. Sci. USA 97, 6013-6018 (2000).

20. Vamosi, G. et al. IL-2 and IL-15 receptor alpha-subunits are coexpressed in a supramolecular receptor cluster in lipid rafts of T cells. Proc. Natl Acad. Sci. USA 101, 11082-11087 (2004).

21. Kondadasula, S. V. et al. Colocalization of the IL-12 receptor and FcgammaRIIla to natural killer cell lipid rafts leads to activation of ERK and enhanced production of interferon-gamma. Blood 111, 4173-4183 (2008).

22. Pierce, S. K. Lipid rafts and B-cell activation. Nat. Rev. Immunol. 2, 96-105 (2002)

23. He, H. T., Lellouch, A. \& Marguet, D. Lipid rafts and the initiation of T cell receptor signaling. Semin. Immunol. 17, 23-33 (2005).

24. Hosszu, K. K. et al. DC-SIGN, C1q, and gC1qR form a trimolecular receptor complex on the surface of monocyte-derived immature dendritic cells. Blood 120, 1228-1236 (2012).
25. Triantafilou, M., Morath, S., Mackie, A., Hartung, T. \& Triantafilou, K. Lateral diffusion of Toll-like receptors reveals that they are transiently confined within lipid rafts on the plasma membrane. J. Cell Sci. 117, 4007-4014 (2004).

26. Xu, S., Huo, J., Gunawan, M., Su, I. H. \& Lam, K. P. Activated dectin-1 localizes to lipid raft microdomains for signaling and activation of phagocytosis and cytokine production in dendritic cells. J. Biol. Chem. 284, 22005-22011 (2009).

27. Pollitt, A. Y. et al. Phosphorylation of CLEC-2 is dependent on lipid rafts, actin polymerization, secondary mediators, and Rac. Blood 115, 2938-2946 (2010).

28. Tilghman, R. W. \& Hoover, R. L. E-selectin and ICAM-1 are incorporated into detergent-insoluble membrane domains following clustering in endothelial cells. FEBS Lett. 525, 83-87 (2002).

29. Cambi, A. et al. Microdomains of the C-type lectin DC-SIGN are portals for virus entry into dendritic cells. J. Cell Biol. 164, 145-155 (2004).

30. Numazaki, M. et al. Cross-linking of SIGNR1 activates JNK and induces TNFalpha production in RAW264.7 cells that express SIGNR1. Biochem. Biophys. Res. Commun. 386, 202-206 (2009).

31. Kim, K. B. et al. Proteome analysis of adipocyte lipid rafts reveals that gC1qR plays essential roles in adipogenesis and insulin signal transduction. Proteomics 9, 2373-2382 (2009)

32. Lobner, M., Leslie, R. G., Prodinger, W. M. \& Nielsen, C. H. Spontaneous complement activation on human B cells results in localized membrane depolarization and the clustering of complement receptor type 2 and C3 fragments. Immunology 128, e661-e669 (2009).

33. Ludford-Menting, M. J. et al. The reorientation of T-cell polarity and inhibition of immunological synapse formation by CD46 involves its recruitment to lipid rafts. J. Lipids 2011, 521863 (2011).

34. Legembre, P., Daburon, S., Moreau, P., Moreau, J. F. \& Taupin, J. L. Modulation of Fas-mediated apoptosis by lipid rafts in T lymphocytes. J. Immunol. 176, 716-720 (2006).

35. Koppel, E. A., Saeland, E., de Cooker, D. J., van Kooyk, Y. \& Geijtenbeek, T. B. DCSIGN specifically recognizes Streptococcus pneumoniae serotypes 3 and 14 Immunobiology 210, 203-210 (2005).

36. Lanoue, A. et al. SIGN-R1 contributes to protection against lethal pneumococcal infection in mice. J. Exp. Med. 200, 1383-1393 (2004).

37. Geijtenbeek, T. B. et al. Identification of DC-SIGN, a novel dendritic cell-specific ICAM-3 receptor that supports primary immune responses. Cell 100, 575-585 (2000).

38. Park, C., Arthos, J., Cicala, C. \& Kehrl, J. H. The HIV-1 envelope protein gp120 is captured and displayed for B cell recognition by SIGN-R1(+) lymphnode macrophages. elife 4, e06467 (2015).

39. Kang, Y. S. et al. A dominant complement fixation pathway for pneumococcal polysaccharides initiated by SIGN-R1 interacting with C1q. Cell 125, 47-58 (2006).

40. Staubach, S. \& Hanisch, F. G. Lipid rafts: signaling and sorting platforms of cells and their roles in cancer. Expert Rev. Proteom. 8, 263-277 (2011).

41. Kang, Y. S. et al. The C-type lectin SIGN-R1 mediates uptake of the capsular polysaccharide of Streptococcus pneumoniae in the marginal zone of mouse spleen. Proc. Natl Acad. Sci. USA 101, 215-220 (2004).

42. Kang, Y. S. et al. SIGN-R1, a novel C-type lectin expressed by marginal zone macrophages in spleen, mediates uptake of the polysaccharide dextran. Int. Immunol. 15, 177-186 (2003).

43. O'Riordan, K. \& Lee, J. C. Staphylococcus aureus capsular polysaccharides. Clin. Microbiol. Rev. 17, 218-234 (2004).

44. Elomaa, $\mathrm{O}$. et al. Cloning of a novel bacteria-binding receptor structurally related to scavenger receptors and expressed in a subset of macrophages. Cell 80, 603-609 (1995).

45. Dam, T. K. \& Brewer, C. F. Lectins as pattern recognition molecules: the effects of epitope density in innate immunity. Glycobiology 20, 270-279 (2010).

46. Cragg, M. S. et al. Complement-mediated lysis by anti-CD20 mAb correlates with segregation into lipid rafts. Blood 101, 1045-1052 (2003).

47. Golan, M. D., Burger, R. \& Loos, M. Conformational changes in C1q after binding to immune complexes: detection of neoantigens with monoclonal antibodies. J. Immunol. 129, 445-447 (1982).

48. Prabagar, M. G. et al. SIGN-R1, a C-type lectin, enhances apoptotic cell clearance through the complement deposition pathway by interacting with $\mathrm{Cla}$ in the spleen. Cell Death Differ. 20, 535-545 (2013).

49. Wouters, D. et al. Complexes between C1q and C3 or C4: novel and specific markers for classical complement pathway activation. J. Immunol. methods 298, 35-45 (2005). 
50. Messmer, B. T. \& Thaler, D. S. C1q-binding peptides share sequence similarity with C4 and induce complement activation. Mol. Immunol. 37, 343-350 (2000).

51. Hey, Y. Y. \& O'Neill, H. C. Murine spleen contains a diversity of myeloid and dendritic cells distinct in antigen presenting function. J. Cell. Mol. Med. 16, 2611-2619 (2012)

52. Agarwal, V. et al. Binding of Streptococcus pneumoniae endopeptidase O (PepO) to complement component C1q modulates the complement attack and promotes host cell adherence. J. Biol. Chem. 289, 15833-15844 (2014).

53. Law, S. K. \& Dodds, A. W. The internal thioester and the covalent binding properties of the complement proteins C3 and C4. Protein science: a publication of the Protein. Protein Sci. 6, 263-274 (1997).

54. Noris, M. \& Remuzzi, G. Overview of complement activation and regulation. Semin. Nephrol. 33, 479-492 (2013).

55. Kim, Y. U. et al. Covalent binding of C3b to C4b within the classical complement pathway C5 convertase. Determination of amino acid residues involved in ester linkage formation. J. Biol. Chem. 267, 4171-4176 (1992).

56. Takata, Y. et al. Covalent association of C $3 \mathrm{~b}$ with C4b within C5 convertase of the classical complement pathway. J. Exp. Med. 165, 1494-1507 (1987).

57. Kerekes, K., Prechl, J., Bajtay, Z., Jozsi, M. \& Erdei, A. A further link between innate and adaptive immunity: C3 deposition on antigen-presenting cells enhances the proliferation of antigen-specific $T$ cells. Int. Immunol. 10 1923-1930 (1998).

58. Ziccardi, R. J. Control of C1 activation by nascent C3b and C4b: a mechanism of feedback inhibition. J. Immunol. 136, 3378-3383 (1986).

59. Baxendale, $H$. E et al. Natural human antibodies to pneumococcus have distinctive molecular characteristics and protect against pneumococcal disease. Clin. Exp. Immunol. 151, 51-60 (2008).

60. Hyams, C., Camberlein, E., Cohen, J. M., Bax, K. \& Brown, J. S. The Streptococcus pneumoniae capsule inhibits complement activity and neutrophil phagocytosis by multiple mechanisms. Infect. Immun. 78, 704-715 (2010).
61. Silva-Martin, N. et al. Structural basis for selective recognition of endogenous and microbial polysaccharides by macrophage receptor SIGN-R1. Structure 22 1595-1606 (2014)

62. Brown, J. S. et al. The classical pathway is the dominant complement pathway required for innate immunity to Streptococcus pneumoniae infection in mice. Proc. Natl Acad. Sci. USA 99, 16969-16974 (2002).

63. Deniset, J. F., Surewaard, B. G., Lee, W. Y. \& Kubes, P. Splenic Ly6G(high) mature and Ly6G(int) immature neutrophils contribute to eradication of S. pneumoniae. J. Exp. Med. 214, 1333-1350 (2017).

64. Wara, D. W. Host defense against Streptococcus pneumoniae: the role of the spleen. Rev. Infect. Dis. 3, 299-309 (1981).

65. Yuste, J. et al. Impaired opsonization with C3b and phagocytosis of Streptococcus pneumoniae in sera from subjects with defects in the classical complement pathway. Infect. Immun. 76, 3761-3770 (2008).

66. Marzi, A. et al. DC-SIGN and DC-SIGNR interact with the glycoprotein of Marburg virus and the $S$ protein of severe acute respiratory syndrome coronavirus. J. Virol. 78, 12090-12095 (2004).

67. Frison, N. et al. Oligolysine-based oligosaccharide clusters: selective recognition and endocytosis by the mannose receptor and dendritic cell-specific intercellular adhesion molecule 3 (ICAM-3)-grabbing nonintegrin. J. Biol. Chem. 278, 23922-23929 (2003).

68. Callegaro-Filho, D., Shrestha, N., Burdick, A. E. \& Haslett, P. A. A potential role for complement in immune evasion by Mycobacterium leprae. J. Drugs Dermatol. 9. 1373-1382 (2010).

69. Borschukova, O. et al. Complement fragment C3d is colocalized within the lipid rafts of T cells and promotes cytokine production. Lupus 21, 1294-1304 (2012).

70. Van Hamme, E., Dewerchin, H. L., Cornelissen, E., Verhasselt, B. \& Nauwynck, H. J. Clathrin- and caveolae-independent entry of feline infectious peritonitis virus in monocytes depends on dynamin. J. Gen. Virol. 89, 2147-2156 (2008). 